\title{
Rhetoric, Dialectic and Logic: The Wild- Goose Chase for an Essential Distinction
}

\author{
ChaRlotTe JøRGenSen
}

Department of Media, Cognition and Communication

Faculty of Humanities

University of Copenhagen

Karen Blixens Vej. 4

DK-2300 København $S$

chlt@hum.ku.dk

\begin{abstract}
Taking Blair's recent contribution to the debate about the triad as its starting point, the article discusses and challenges attempts to reduce the intricate relationship between rhetoric, dialectic and logic to a trichotomy with watertight compartments or to separate them with a single clear-cut criterion. I argue that efforts to pinpoint an essential difference, among the various typical differences partly grounded in disciplinary traditions, obscure the complexities within the fields. As a consequence, crosscutting properties of the fields as well as the possibilities for theoretical bridging between them are neglected.
\end{abstract}

Résumé: Je prends comme point de départ la récente contribution de Blair au débat sur la rhétorique, la dialectique et la logique et je conteste les tentatives de réduire leurs interrelations à une trichotomie formée de compartiments étanches ou les tentatives de séparer ces trois domaines de l'argumentation avec un seul critère clair. Je soutiens que les efforts d'identifier une différence essentielle entre les différences typiques partiellement fondées sur les traditions disciplinaires masquent leur complexité dans les disciplines. En conséquence, les propriétés transversales de ces disciplines ainsi que les possibilités de pontage théorique entre elles sont negligees.

Keywords: argumentation theory, Christian Kock, dialectic, fields of argument, J. Anthony Blair, logic, rhetoric, Wenzel's perspectives on argument

\section{Introduction}

This article continues the debate about the relation between the three traditional fields of argumentation theory rhetoric, dialectic and logic, taking the recent contribution on the issue by Blair (2012) as its starting point. ${ }^{1}$ Blair challenges Wenzel's

\footnotetext{
${ }^{1}$ The current article is based on a paper presented at the $10^{\text {th }}$ OSSA conference at the University of Windsor, 2013 and is a revision of the publication in the Proceedings (JøRGENSEN 2014).
}

(C) Charlotte Jørgensen, Informal Logic, Vol. 34, No. 2 (2014), pp. 152-166. 
widespread view (1990) that the difference resides in three perspectives, relating to process, procedure, and product. He furthermore questions the alternative view proposed by especially Kock (2009) that the distinguishing feature is the topical domain of the field. Blair then introduces his alternative: rhetoric studies arguments in speeches, dialectics in conversations, and logic studies good reasoning in both.

I share many of his points and objections to the views of others on the issue, but disagree with Blair's proposed division. When I argue against this division - and Kock's as well - in what follows, my main purpose is to challenge any effort to reduce the intricate relationship between the fields of the triad to a watertight trichotomy or a single criterion. While I endorse the traditional listing of typical differences and similarities to characterize their mutual relation, I regard the attempt to emphasize one of them as the significant distinguishing feature as a wild-goose chase. Like Johnson (2009), I find that efforts of this kind obscure the complexities within the fields of the triad, and that many of the differences between them are due to our respective disciplinary traditions. Moreover, I suggest that in the pursuit of the essential difference between the fields we risk bypassing the intermingling and the overlap of rhetoric, dialectic and logic and, in turn, the possibilities for theoretical bridging between them.

In section two and three below, I discuss the distinctions proposed by Blair and Kock. In the fourth section I discuss some implications of reducing the differences between the three fields and suggest how we should approach the relationship between them instead. Before I proceed, however, a few preliminary terminological remarks and demarcations are appropriate.

The first remark concerns the terms we use to designate rhetoric, dialectic and logic and the relationship between them. Are they 'disciplines', 'arts', 'sciences', 'research traditions', or 'perspectives', etc.? Johnson (2009, pp. 5, 18), for instance, insists that dialectic nowadays is not a discipline, presumably because it is not taught in university curricula as it was in the past. He also calls attention to the fuzziness of Wenzel's concept perspectivism, referring (in note 4) to Hans Hansen, who in discussion asked: What is a perspective? Johnson admits the relevance of the question but leaves it at that, using expressions such as the three 'approaches' (e.g., p. 8) and 'communities (of inquiry)' (pp. 11-12). Since I argue against a tendency to 
compartmentalize rhetoric, dialectic and logic, I find that such elastic terms suit my purpose and call them 'fields'.

Furthermore, I use the term 'triad' when referring collectively to these fields. I wish to underscore that my focus on the three fields does not imply any intention to exclude approaches to argumentation from other fields of study. In other words, I share Johnson's concern that Wenzel's tripartite standard model conceived in The Triumvirate View runs the risk of supporting "exclusivist tendencies". The fact that the three classical traditions have dominated argumentation theory in a broad historical perspective of course does not mean that we, in our modern context, should not welcome contributions from other fields, for instance, communication, linguistics, computer science, psychology, political theory, or law (cf. Johnson 2009, p. 7).

\section{Blair's tripartite distinction}

The first sections of J. Anthony Blair's article "Rhetoric, Dialectic, and Logic as Related to Argument" (2012) progress as a critique of the Wenzel distinction (1990) process-procedureproduct that has become a standard model for characterizing the perspectives pertaining to respectively rhetoric-dialectic-logic. Blair convincingly points out various problems and shortcomings of this 'perspectival model' that arise when subjecting it to closer inspection. Moreover, he argues that, although Aristotle is "no doubt the source of the logic/dialectic/rhetoric trichotomy", he considers it "a stretch to say" that Aristotle in the Prior Analytics, Topics and Rhetoric presents three perspectives on argumentation (pp. 154-155). The expression 'stretch' indicates that 'perspectives' is not far off the mark, either. In some of its senses, the word seems appropriate to characterize the Aristotelian view of the relation between the three fields. When, for instance, Aristotle in the opening sentence of his Rhetoric describes rhetoric as 'antistrophe' to dialectic, this comes close to saying in modern terms that they represent two perspectives on argument. In using that theatrical and metrical metaphor, Aristotle - alluding subtly to Plato - places the two argumentative fields on a par, at the same time mirroring and contrasting each other because of the likenesses they share, and the differences with which they supplement each other (cf. Kennedy note 2, pp. 28-29). Moreover, it may be maintained that Aristotle, being "interested in the laws of deduction, strategies for winning dialogue games, 
and methods for persuasive speeches, respectively" (Blair p. 155), represents a perspectival view at least in the sense that all three aspects are relevant for argumentative practice and that none of them alone suffices as a universal argumentation theory.

After the cautious conclusion that he considers it "an anachronism to find in Aristotle the thesis that logic, dialectic and rhetoric are three perspectives on argumentation" (p. 155), Blair next turns to what he considers an alternative to Wenzel's perspectival model, proposed by Kock (2009) and shared, at least partly, by Tindale (1999) and Hauser (2002), namely the view that the main difference between the fields is their topical domain. I shall return to this alternative in section three below.

Finding both models inadequate for capturing the relationship within the triad, Blair in his final section (pp. 157162) replaces them with his own model. Briefly stated, rhetoric concerns arguments in speeches, dialectic concerns arguments in conversations, and logic concerns good reasoning in speeches as well as conversations. He unfolds this trichotomy in two steps. First, he discusses the relation between rhetoric and dialectic, and next, suggests how logic is related to both of them. In what follows, I address Blair's trichotomy in this order.

Taking his cue from Krabbe (2000), Blair shifts the distinctive feature to the "kind of discourse", i.e., the communicative format associated with the two fields, in particular the roles of the participants involved in the argumentative set-up: rhetorical speeches are instances of unilateral communication from an arguing rhetor to a heterogeneous mass audience; dialectical conversations are turntaking argumentative discourse between two directly interacting interlocutors. Blair demonstrates the contrast with the following suggestion:

$[\mathrm{I}] \mathrm{t}$ is the noninteractive and diverse nature of the addressee in speeches that gives rise to the complex of properties typically associated with rhetoric, whereas it is the interactive and homogeneous nature of the interlocutor in conversations that gives rise to the complex of properties typically associated with dialectic. And it is these differences that in turn affect the rhetorical and the dialectical properties of the arguments in the two venues. (p. 161)

My first objection to this portrayal of the relationship between rhetoric and dialectic coincides with Johnson's fundamental reaction to the standard Wenzel trichotomy, namely that there is 
no such thing as the rhetorical, dialectical, or logic perspective. ${ }^{2}$ That Blair is well aware of this misconception of the triad is clearly stated in the introduction, where he cites Johnson's "principal concern $[\ldots]$ that there is in each case no single rhetorical, dialectical or logical perspective" but "many different, and sometimes incompatible, understandings of each", and that to imply otherwise is a "misleading oversimplification". Blair thus concedes that there are many rhetorics, etc. Yet, he maintains that "despite the internal differences among conceptions of rhetoric, dialectic and logic" one may nonetheless hold the view that there are three broad perspectives, since "[t]he quarreling logicians can be distinguished from the quarreling dialecticians, and both can be distinguished from the quarreling rhetoricians" (pp. 149-150).

Part of the way, Blair is of course right. However, if we make one feature the essential one, should we not then expect that this is indeed something that the members of each field, despite their internal quarrels, can agree on - at least in general terms? My reply to this question is that most rhetoricians will oppose the suggestion that rhetorical argumentation is confined to speeches or that speeches are more important to rhetoric than other types of discourse. Granted, no rhetorician will deny that speeches play an important role among the types of discourse studied by rhetoric, but no rhetorician inside academia would claim that speeches are, as a matter of principle, more essential to rhetoric than for instance written discourse. To identify rhetoric with speeches may be truer in relation to classical rhetoric than to modern rhetoric, and no one can deny that the theory of rhetoric emerged in connection with speeches. However, many would argue that this was because speech communication was the prevailing medium for public address in antiquity, but that this does not mean that rhetorical discourse has to be oral. Frentz' analysis of the film My Dinner with Andre "as a paradigm example of a rhetorical conversation" (Frentz, p. 295) may serve as an illustration of rhetorical criticism that encompasses much more than the sustained oral and written discourse associated with mainstream rhetoric.

\footnotetext{
${ }^{2}$ Although Johnson is right in calling attention to the misconception that there is unanimity within each field, this objection represents a misreading of Wenzel. It seems incompatible with the pluralistic approach that pervades his recommendation of adopting a perspectival view. Wenzel (1990) certainly acknowledges the diversity within the fields, referring for instance to "the many other approaches to rhetorical theory in modern times" (p. 21), cf. Gilbert (2014) who points out that Wenzel has used the expression "chief perspectives" indicating that they are not the only ones (p. 2).
}

(C) Charlotte Jørgensen, Informal Logic, Vol. 34, No. 2 (2014), pp. 152-166. 
I am aware that I am perhaps treating Blair's distinction too literally. In connection with the observation that audiences to speeches do not respond the same way as partners in a conversation, Blair points out that in this respect "[p]ublished argumentation, such as found in magazines or academic or scientific journal articles or books, is more closely related to speeches than to conversations". If 'speeches' were used as a term that includes such written artefacts, this would be an improvement from a rhetorical point of view. But in that case, why not use more precise terms, phrasing the difference between rhetorical and dialectical argumentation as a matter of one-way or two-way communication? Perhaps this option is unattractive because it spoils the symmetry in Blair's connection of dialectic with turn-taking discussions in oral face-to-face communication. On the other hand, others might object to this and hold the view, as I do, that dialectical approaches are not restricted to oral situations. Pragma-dialecticians, for instance, apply their argumentation theory to many other kinds of texts than oral turn-taking discussions. An example is van Eemeren and Houtlosser's analysis (2002) of Shell's worldwide newspaper advertorial in defense of the company's involvements in Nigeria (see Leff 2006), a text that certainly better fits the rhetorical situation than the dialectical communicative situation described by Blair.

My account of Blair's view may also be overly critical for another reason. In the conclusion, he uses the expression that "in argumentation rhetoric and dialectic reflect different paradigmatic contexts" and speaks about "typically rhetorical and typically dialectical contexts" (p.162, emphasis added). These modifiers obviously lessen the distance between Blair's and my view and may be understood as an opening towards the objections I have raised. In that case, the issue still depends on the sense in which we use the word 'paradigm'. Does it mean that speeches vs. conversations are paradigms in a historical sense, i.e., that the fields of argumentation theory have developed and attained their respective properties as a result of the two typical practical contexts? Or does 'paradigmatic' refer to quintessential or archetypical contexts in a contemporary or a-historical sense? In the first case, Blair's distinction is appropriate as a general characterization of the two fields. In this sense, the trichotomy corresponds pretty well with Johnson's view - and mine - that members of each community of study are "bound together by a common history, tradition, education, and an ongoing interest in a wide range of issues and problems." (Johnson 2009, p. 11) 
However, as I read Blair's article, the trichotomy is primarily suggested as a relevant delineation of the contemporary relation between the fields. And in this second case where 'paradigm' refers to the quintessential type of text studied, the distinction speeches versus conversations narrows the domains of the respective fields in ways that at least rhetoricians, regardless of orientation, cannot identify with.

I have some further specific reservations about what constitutes the typical rhetorical speech situation. According to Blair (cf. the passb from p. 161 quoted above), speeches are monologues addressed to a usually heterogeneous mass audience. As he has pointed out in "The Limits of the Dialogue Model of Argument", speeches are only dialogical in a metaphorical sense (1998, p. 337), although they are (explicitly or implicitly) dialectical, i.e., they relate to counter-arguments. I find this distinction appropriate and illuminating, but I do not think that Blair's contrast in the present article pays sufficient tribute to the complexity of the rhetorical speech situation and the role of audiences. Speeches are of course formally monological in so far as the rhetor has the floor; and the audience is 'non-interactive' in so far as the audience members attend the speech as listeners and do not interact as arguers. But in another sense many rhetorical situations are not monological; they are trialogical (as for the German term 'trialogisch', see Dieckmann, p. 218, and Klein, pp. 355-356). They take place in settings involving three interacting parties: two arguers and a decision-making audience (cf. Bitzer: 'mediators of change'). The audience plays a vital role in the interaction in a capacity that renders the audience constitutive to the argumentative situation. Thus the paradigmatic context of 'pure' deliberative rhetoric is a trialogical debate situation. In contrast, the 'pure' dialectical situation is dialogical as defined by Blair, and in regard to the constellation of participants as well. Only the two discussants constitute this kind of discourse, whether attended by an audience or not. The point is that a present dialectical audience act as bystanders, not as constituents in the argumentative setting, i.e., the audience makes no difference to the development of the critical discussion, the performance of the arguers or the outcome of the interaction (Jørgensen 1995; 1998, pp. 438-439; Kock 2007, p. 109). Note that the word 'pure' is inserted above in order to leave room for the many overlapping and mixed situations between the two paradigms that both Krabbe (2000) and Blair himself in the earlier article (1998) have shed light on in ways that are consistent with my own approach to the issue here.

(C) Charlotte Jørgensen, Informal Logic, Vol. 34, No. 2 (2014), pp. 152-166. 
A second reservation concerns the composition and size of rhetorical audiences. Agreed, public speeches are typically addressed to large audiences, consisting of more or less diverse segments, and the notion homogeneous is always relative when it comes to audiences consisting of several or many members. But speeches may just as well be delivered to a fairly homogeneous group of individuals, for instance experts in a certain field or a political group, and this does not make the speech less typical as rhetorical discourse. Rhetorical audiences do not have to be a mass audience either. The audience is often a small group, sometimes only a single person or even the rhetor him- or herself, in which case we have 'self-deliberation' (Perelman \& Olbrechts-Tyteca, § 8-9).

Having discussed rhetoric versus dialectic, Blair deals rather summarily with logic. By the definition that 'logic' "is more widely understood as consisting of (the study of) the norms of good reasoning", he suggests that "the logic of arguments will consist of the appropriate norms of the reasoning exhibited in, or invited by, arguments used in argumentation", whether in speeches or conversations. Further, he points out that each of the three fields has "both a descriptive and a normative branch" (p. 161-162). Thus I reckon that Blair does not suggest that logic is needed to provide dialectic and rhetoric with norms for good arguing/arguments/argumentation broadly speaking, but only with those norms that concern reasoning. This opens the question of how 'reason' is defined. Does it refer more narrowly to 'rationality' and the criteria associated with traditional formal logic and inferential informal logic, e.g., deductive validity, soundness, inductive strength, etc.? I gather that this is rather how we should understand Blair's trichotomy. In his conclusion, however, he does use the expression with broader connotations: logic is the study of "the norms of reasonableness of arguments" (p. 162). If reasonableness refers to an enlarged notion of rationality as advanced by Perelman (Perelman \& Olbrecths-Tyteca 1969; Perelman 1984) or Toulmin $(1958,1981,2001)$, the delegation of these norms to logic becomes problematic. In my rhetorical view, one cannot separate reasonableness from good argumentation, but 'reasonable' means 'legitimate' or 'acceptable' rather than 'correct' according to certain universal logical standards, no matter how they are defined (cf. Tindale). Legitimacy and acceptability embrace, among other things, ethical argumentative conduct and considerations relating to the substance of the arguments, including the merits of the opinions and values appealed to. Such norms (for instance the 'standard 
of fairness', Jørgensen 2007) cannot be what Blair has in mind for logic, since that would mean that in order to be a logician one should first be both a rhetorician and a dialectician.

\section{Kock's distinction}

We now shift the attention to the distinction between the fields that Blair, as mentioned, discusses as an alternative to Wenzel's standard model, referring specifically to Christian Kock's paper "Choice is Not True or False: The Domain of Rhetorical Argumentation" (2009). Kock makes "the kind of argument", the "subject matter" or "the topical domain" the distinctive feature that characterizes rhetorical argumentation (Blair, pp. $153,155)$ - i.e., the kind of issue argued about. Kock (2007, 2009) actually does not make a tripartite distinction between the fields. Instead he proposes a distinction between, on the one hand, practical argumentation designed for issues of action, and on the other, argumentation designed to establish questions of fact. Rhetorical argumentation is "centrally concerned with choice of action" (2009, p. 65). Action-related argumentation involves values, and claims about action and values are not true or false. The distinction thus rests on a dichotomy between issues that have truth-value and issues that do not. Whereas the domain of rhetoric is choice of action, the domain of logic and dialectic presumably is centered on issues of fact.

Blair (p. 156) raises two objections to Kock's view, of which I shall only consider the first, namely the implication that rhetoric should not be committed to truth. On the one hand, it can hardly be claimed that Kock carries his view to such an extreme. He explicitly makes allowance for the obvious fact that a rhetor's main proposal for action "may be supported by propositions that can be true (or probable)" (Kock 2009, p. 76). At this level of the argumentative context rhetoric of course is committed to truth, and if Kock were denying this, it would be absurd. On the other hand, the objection is relevant in relation to the implication that rhetorical argumentation should be limited to the domain that has a proposal of choice as its main (implicit or explicit) claim in the specific situation. Although Kock nowhere claims explicitly that rhetorical argumentation is exclusively restricted to choice and "actions within our own" ( $p$. 62), his insistence on the dominant importance of the dichotomy strongly invites the reader to draw this conclusion. But an equation between rhetorical argumentative discourse and the domain of choice is an over-simplification, and hence the 
distinction choice of action - truth of facts is too narrow, drawing a sharper line between the fields than is appropriate from my point of view. In this respect, Kock's and Blair's alternative models are two of a kind.

In connection with his proposed equation, it seems odd that Kock advocates a narrow conception of rhetorical argumentation compared to the broad view of rhetoric that he represents. The discrepancy is evidenced by his introductory remarks about the wide scope of rhetoric (p. 62). He declares his broad view, quoting George Campbell's famous definition in order to emphasize that the ends of rhetorical discourse are multiple, and that argumentation is only part of rhetoric. For example, he says, the aim to please the imagination "would not belong to the subject matter of argumentation theory." However, another of the four ends, namely to enlighten the understanding, very often requires argumentation, also in communicative situations that fall within the discursive field of rhetoric. For example a rhetor might seek to explain to a novice how a technical device works, or explain it to someone who believes that it works in a different way. In such cases, the issue is not a choice; the rhetor's main claim is a matter of fact - true or false, and the rhetor will produce arguments, either by demonstrative reasoning or by convincing/persuading in the attempt to overcome the divergence of belief.

The counter-example merely serves to refute the claim that rhetorical argumentation is confined to issues of action. Its purpose is not to contradict the fact that deliberative rhetoric is typically value-based action-related argumentation, or that this kind of argumentation has been the dominant paradigm for rhetorical argumentation theory throughout history - and still is for deliberative rhetoric in particular. Moreover, as I read Kock, his main aim is not to make a division that separates rhetoric from the other fields in the triad. It is, rather, to promote the understanding that we argue differently in the two domains, and that accordingly the critic cannot apply one and the same theoretical description to them both, or evaluate argumentation belonging to these two domains by the same norms and standards. If this interpretation holds, I fully agree with Kock's point of view. And this brings me to the last section about the implications concerning the relationship between the fields in the triad and why I suggest that we stop reducing their differences to a single feature. 


\section{Implications}

I have argued that in pursuing the essential difference we are bound to end up presenting the relationship in ways that members of the fields cannot identify with - ways which gloss over their intermingling properties, and which contradict the pluralism of each field as well as the possibility for individual theoretical bridging between the fields.

It is an academic topos that scholarly progress is sometimes achieved by a step backwards rather than forwards. It is another topos that scholarly work by nature involves reduction to some degree. The question is when our reductions bring fruitful insight and order to the complexities of reality, and when they transgress this line by over-simplifying them. As Gilbert phrases it, we should treat distinctions for what they are - "not a description of reality, but rather an aid to understand Argumentation Theory" - not changing them into separations (Gilbert, p. 2). Both topoi are relevant to my position concerning the relation between the fields of the triad.

I suggest that we go back to listing the various typical traditional differences and similarities between rhetoric, dialectic and logic, and stop searching for the essential difference. To my mind, such lists serve a pedagogical purpose. The lists are the kind that for instance Leff (2000) presents, covering items such as subject, purpose, scope, sphere, legitimacy of intellectual and emotional appeals, communicative interaction formats, style, etc. McAdon's chart, depicting the three fields in the context of Aristotle's thinking, is another example, comparing them with respect to participants, audience, realm/practise, purpose, methodology, starting points, reasoning tools (McAdon, p. 150). In accordance with Johnson's view, they also help us understand what we who belong to one of the fields come from, build upon and have in common, and how our fields relate to one another in a larger perspective.

Now, all the properties of the fields on such lists are more or less typical, and in each field we find exceptions. As long as we present a set of typical points of comparison, the chances are that they do not harm the understanding of the complexities of the triad. But the further we reduce their number, in particular if we exalt one of them to the essential feature, the further we run the risk of gross simplifications and misrepresentations of the state of our art.

In Leff's words, we thus run the risk of "compartmentalized purity" (2006, p. 199), in contrast to how modern argumentation theory has in fact developed. As Leff, in this connection, points 
out there has been a general tendency of integration within the field of argumentation theory. Perelman's New Rhetoric integrates rhetoric with dialectic in this hierarchical order; Pragma-Dialectic in its later phase does too, but subsumes rhetoric, using the term 'strategic maneuvering', under dialectic; Johnson's theory of Manifest Rationality (2000) combines informal logic with a dialectical approach, and so forth.

Let me in conclusion indicate the kind of pluralism that I advocate, and my view of the integration of argumentation theories. None of the three fields alone is able to capture the diversity of argumentative discourse. They supplement one another, and whichever field or theoretical combinations we employ depends on our individual background within (or outside) the triad, our theoretical orientation, the kind of discourse or the argumentative artefact we study, the aspect or the research question we investigate, etc. The ubiquity and diversity of the argumentative act in human communication renders the field of argumentation too multifaceted to be covered by one of the fields (or by the triad as a whole). It takes all sorts to make the world, as the saying goes, which does not relieve us of the individual choice of the appropriate 'sort' that serves the purpose in each case. Acknowledging the pluralism of argumentation theory of course does not mean that anything goes for the critic. While I endorse theoretical pluralism and the indicated kind of integrating views, I do, however, oppose the kind of integration that seeks universal argumentative theories (Jørgensen 2009). Thus, because of the multifarious nature of argumentative discourse, I agree with Kock's fundamental view, namely that we cannot approach the two domains he outlines by the same descriptive apparatus and evaluative norms. And to end with another example, I fully agree with Blair's point of view (1998) when he challenges theories that have dialogue as descriptive and normative paradigms: It does matter in both respects whether we consider sustained speeches or turn-taking conversations.

Acknowledgements: I thank Professor Michael Gilbert and the anonymous referee for their constructive comments on the conference paper and the revised manuscript. 


\section{References}

Bitzer, L.F. (1968). "The Rhetorical Situation.” Philosophy and Rhetoric 1, 1-14. (Reprint in Supplementary Issue 1992, 114.)

Blair, J.A. (1998). "The Limits of the Dialogue Model of Argument." Argumentation 12, 325-339.

Blair, J.A. (2012). "Rhetoric, Dialectic, and Logic as Related to Argument." Philosophy and Rhetoric 45, 148-164.

Dieckmann, W. (1981). Politische Sprache, politische Kommunikation. Heidelberg: Carl Winter Universitätsverlag.

Eemeren, F.H. van \& P. Houtlosser (2002). "Strategic Maneuvering: Maintaining a Delicate Balance." In: F.H. van Eemeren \& P. Houtlosser (Eds.), Dialectic and Rhetoric: The Warp and Woof of Argument Analysis (pp. 131-159). Dordrecht: Kluwer Academic Publishers.

Frentz, T.S. (1999) [1985]. "Rhetorical Conversation, Time, and Moral Action." In J.L. Lucaites, C.M. Condit \& S. Caudill (Eds.), Contemporary Rhetorical Theory: A Reader (pp. 288305). New York: The Guilford Press.

Gilbert M.A. (2014). “Commentary on: Charlotte Jørgensen's "Rhetoric, Dialectic, and Logic: The Triad Decompartmentalized." In D. Mohammed \& M. Lewinski (Eds.), Virtues of Argumentation. Proceedings of the $10^{\text {th }}$ International Conference of the Ontario Society for the Study of Argumentation (OSSA), 22-26 May 2013. (CD-ROM, pp. 1-4) Windsor, ON: OSSA.

Hauser, G.A. (2002). Introduction to Rhetorical Theory. Second Edition. Prospect Heights: Waveland Press.

Johnson, R.H. (2000). Manifest Rationality: A Pragmatic Theory of Argument. Mahwah, N.J.: Lawrence Erlbaum Associates.

Johnson, R.H. (2009). "Revisiting the Logical/dialectical/rhetorical Triumvirate.” In: J. Ritola (Ed.), Argument Cultures: Proceedings of OSSA 09. (CD-ROM, pp. 1-13) Windsor: Ontario Society for the Study of Argumentation.

Jørgensen, C. (1995). "Debattens væsen og uvæsen: Om fjendtlighed i offentlig debat." Retorik Studier 10, 3-43.

Jørgensen, C. (1998). "Public Debate - An Act of Hostility? Argumentation 12, 431-443.

Jørgensen, C. (2007). The Relevance of Intention in Argument Evaluation." Argumentation 21, 165-174. 
Jørgensen, C. (2009). “Argumentation.” In C. Jørgensen \& L. Villadsen (Eds.), Retorik. Teori og praksis (pp. 129-158, Ch. 7). Copenhagen: Samfundslitteratur.

Jørgensen, C. (2014). "Rhetoric, Dialectic and Logic: The Triad De-compartmentalized." In D. Mohammed \& M. Lewinski (Eds.), Virtues of Argumentation. Proceedings of the $10^{\text {th }}$ International Conference of the Ontario Society for the Study of Argumentation (OSSA), 22-26 May 2013. (CD-ROM, pp. 1-9) Windsor, ON: OSSA.

Kennedy, G.A. (1991). Aristotle On Rhetoric: A Theory of Civic Discourse. New York: Oxford University Press.

Klein, J. (1991). "Zur Rhetorik politischer Fernsehdiskussionen. "In G. Ueding (Ed.), Rhetorik zwischen den Wissenschaften. Geschichte, System, Praxis als Probleme des "Historischen Wörterbuchs der Rhetorik" (pp. 353-362), Tübingen: Max Niemeyer Verlag.

Kock, C. (2007). "Norms of Legitimate Dissensus." Informal Logic 27, 179-196.

Kock, C. (2009). "Choice is not True or False: The Domain of Rhetorical Argumentation." Argumentation 23, 61-80.

Krabbe, C.W. (2000). "Meeting in the House of Callias: Rhetoric and Dialectic." Argumentation 14, 205-217.

Leff, M. (2000). "Rhetoric and Dialectic in the Twenty-first Century." Argumentation 14, 241-254.

Leff, M. (2006). "Rhetoric, Dialectic, and the Functions of Argument." In P. Houtlosser et al. (Eds), Considering Pragma-Dialectics: A festschrift for Frans $H$. van Eemeren on the occasion of his $60^{\text {th }}$ birthday (pp. 199-209, Ch. 17). Mahwah, N.J.: Lawrence Erlbaum Associates.

McAdon, B. (2001). "Rhetoric is Counterpart of Dialectic" (" $\mathrm{H}$

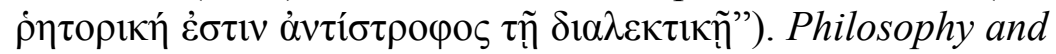
Rhetoric 34, 113-150.

Perelman, C. (1984). "The New Rhetoric and the Rhetoricians: Remembrances and Comments." Quarterly Journal of Speech 70, 188-196.

Perelman, C. \& L. Olbrechts-Tyteca (1969). The New Rhetoric. A Treatise on Argumentation. Notre Dame: University of Notre Dame Press.

Tindale, C.W. (1999). Acts of Arguing: A Rhetorical Model of Argument. Albany: State University of New York Press.

Toulmin, S. (1958). The Uses of Argument. Cambridge: Cambridge University Press.

Toulmin, S. (1981). "The Tyranny of Principles." The Hasting Center Report 11, 6, 31-39. 
Toulmin, S. (2001). Return to Reason. Cambridge: Harvard University Press.

Wenzel, J. (1990). "Three Perspectives on Argument: Rhetoric, Dialectic, Logic." In R. Trapp \& J. Schuetz (Eds.), Perspectives on Argumentation. Essays in Honor of Wayne Brockriede (pp. 9-26, Ch.2). Prospect Heights: Waveland Press. 